\title{
CARACTERES PRODUTIVOS DE SORGO HÍBRIDO SS-318 SUBMETIDO A DOSES DE NITROGÊNIO
}

\section{Caroline Pimentel Maia ${ }^{1}$, Daniel Parente Barbosa ${ }^{2}$, Luiz Felipe Coelho dos Santos ${ }^{3}$, Nayara Lima Pereira ${ }^{4}$, Andréa Krystina Vinente Guimarães ${ }^{5}$}

\footnotetext{
${ }^{1}$ Universidade Federal do Oeste do Pará, Santarém, Pará, Brasil, carolinepimentelmaia@hotmail.com Universidade Federal do Oeste do Pará, Santarém, Pará, Brasil, danielparenteufopa@gmail.com ${ }^{3}$ Universidade Federal do Oeste do Pará, Santarém, Pará, Brasil, luizfelipe.ufopa@gmail.com ${ }^{4}$ Universidade Federal do Oeste do Pará, Santarém, Pará, Brasil, naylimapereira@gmail.com 5Universidade Federal do Oeste do Pará, Santarém, Pará, Brasil, andreavinente@gmail.com
}

RESUMO: Para obter forragem de qualidade torna-se necessário maneja-la com adubos, em doses e formas adequadas, desta forma, objetivou-se avaliar três doses de nitrogênio sobre as características morfogênicas e produtivas do hibrido de sorgo SS318. O experimento foi realizado no período de junho a setembro de 2015, na Fazenda Experimental da Universidade Federal do Oeste do Pará, com área experimental preparada inicialmente com duas gradagens. O delineamento experimental foi inteiramente casualizado, sendo três tratamentos (80, 120 e $160 \mathrm{~kg} \cdot \mathrm{ha}^{-1}$ de nitrogênio) e quatro repetições. Aos 35 dias foram aferidas as variáveis morfométricas e aos 90 dias foram mensuradas as variáveis morfométricas e produtivas do sorgo. O número de folhas e de perfilhos avaliados aos 35 dias não diferiram estatisticamente $(p>0,05)$, no entanto, a altura apresentou variação entre as doses de nitrogênio, expondo médias de 0,61 a 0,55 m. Aos 90 dias as variáveis: número de folhas vivas, cujas médias variaram de 6,60 a 5,39 folhas.planta-1, número de perfilho, com médias de 1,27 a 0,85 perfilhos.planta-1 e altura, variando de 1,94 a 1,80 m, diferiram significativamente $(p<0,05)$, mas o número de folhas mortas, população de plantas, acamamento, plantas quebradas, matéria verde e matéria seca da folha, colmo e panícula não apresentaram diferenças entre os tratamentos $(p>0,05)$. Não houve incremento nos caracteres produtivos com o aumento das doses de $\mathrm{N}$ acima de $80 \mathrm{~kg}$.ha1

PALAVRAS-CHAVE: Adubação nitrogenada, Biomassa, Matéria seca, Sorghum bicolor.

\section{PRODUCTIVE CHARACTERS SORGHUM HYBRIDS SS-318 SUBMITTED TO LEVELS OF NITROGEN}

ABSTRACT: Aim to obtain quality of forage it is necessary to management it with fertilizers, in appropriate levels and forms, therefore. It was developed a research to evaluate three levels of nitrogen on morphogenic and productive characteristics of sorghum hybrid SS318. The experiment was carried out in the period from June to September, 2015, at the Experimental Farm of UFOPA, the area was prepared with two harrows. The experimental design was completely randomized, with three treatments (80, 120 and $160 \mathrm{~kg}^{\mathrm{h}} \mathrm{ha}^{-1}$ of nitrogen) and four replications. After 35 days post seeding were measured morphometric 
variables and after 90 days were measured morphometric variables and productivity of sorghum. The number of leaves and tillers measured after 35 days did not differ significantly. There was variation of height due to the levels of nitrogen $(0.61$ to $0.55 \mathrm{~m})$. After 90 days, there was differences in this variables: number of live leaves, whose averages ranged from 6.60 to 5.39 leaves. plant ${ }^{-1}$, number of tillers, averaging 1.27 to 0.85 tillers.plant $^{-1}$, and height was ranging from 1.94 to $1.80 \mathrm{~m}$. There was not differences into levels of nitrogen in this variables: number of dead leaves, plant population, bedding, broken plants, green and dry matter of leaf, stem and panicle. There was not increase in productive characters with levels of nitrogen above $80 \mathrm{~kg} \cdot \mathrm{ha}^{-1}$.

KEYWORDS: Biomass, Dry matter, Nitrogen fertilization, Sorghum bicolor.

\section{CARACTERES PRODUCTIVOS DE SORGO HÍBRIDO SS-318 SOMETIDO A DOSIS DE NITRÓGENO}

RESUMEN: Para obtener el forraje de calidad se hace necesario manejarla con abonos, en dosis y formas adecuadas, de esta forma, se objetivó evaluar tres dosis de nitrógeno sobre las características morfogénicas y productivas del híbrido de sorgo SS318. El experimento fue realizado en el período de junio a septiembre de 2015, en la Hacienda Experimental de la Universidad Federal del Oeste de Pará, con área experimental preparada inicialmente con dos gradaciones. El delineamiento experimental fue completamente casualizado, siendo tres tratamientos (80, 120 y 160 kg.ha-1 de nitrógeno) y cuatro repeticiones. A los 35 días se evaluaron las variables morfométricas ya a los 90 días se midieron las variables morfométricas y productivas del sorgo. El número de hojas y de perfiles evaluados a los 35 días no diferían estadísticamente $(p>0,05)$, sin embargo, la altura presentó variación entre las dosis de nitrógeno, exponiendo promedios de 0,61 a 0,55 m. A los 90 días las variables: número de hojas vivas, cuyas promedias variaron de 6,60 a 5,39 hojas.planta-1 ${ }^{-1}$ número de perfil, con promedios de 1,27 a 0,85 perfiles. planta ${ }^{-1}$ y altura, variando de $1,(P<0,05)$, pero el número de hojas muertas, población de plantas, acamamiento, plantas quebradas, materia verde y materia seca de la hoja, colmo y panícula no presentaron diferencias entre los tratamientos $(p>0,05)$. No hubo incremento en los caracteres productivos con el aumento de las dosis de $\mathrm{N}$ por encima de $80 \mathrm{~kg} \cdot \mathrm{ha}^{-1}$.

PALABRAS CLAVE: Biomasa, Fertilización nitrogenada, Materia seca, Sorghum bicolor.

INTRODUÇÃO

O Sorghum bicolor (L.) Moench

pertence a família Poaceae, é uma gramínea de clima tropical, não tolera baixas temperaturas, sendo seu cultivo indicado em regiões com temperatura media superior a $20^{\circ} \mathrm{C}$, tolera ao déficit 
hídrico, solos encharcados e a baixa fertilidade dos solos (BUSO et al., 2012).

○ sorgo possui uma utilização diversificada na produção animal, pode ser usada para pastoreio, silagem, uso dos grãos na formulação de ração, além de ser uma boa opção no plantio direto. Com relação à silagem, o sorgo é uma planta adaptada a esse processo, possui alto valor energético, além de apresentar baixo custo de produção quando incluso na alimentação animal, e maior retorno econômico, principalmente por possui capacidade de rebrota devido às características do seu sistema radicular (REZENDE et al., 2011; BUSO et al., 2012).

O crescimento do cultivo de sorgo no Brasil tem sido lento, principalmente devido as práticas incorretas de manejo, adubações incorretas e escolhas de sementes inadequadas, essas práticas podem comprometer a boa produtividade da forragem e levar a um decréscimo nessa atividade (BASSO et al., 2011).

Em estudo realizado por Gomes et al. (2006) observou-se o comportamento agronômico de alguns cultivares de sorgo (BR 700, VOLUMAX, SHS 500, MASSA 03,
BRS 701, 0698005, AG 2005, BRS 506, 0698007, BR 601 e IPA 467-4-2), após o uso de adubação mineral NPK, na proporção: 60:40:30, encontraram valores para a produção de matéria verde entre 17.637 kg.ha-1 e 57.126 kg.ha-1, percentual de matéria seca de 26,69 a 41,70\% e altura entre 1,52 m e 4,11 m.

Dentre os macronutrientes, o nitrogênio é determinante para a nutrição de plantas, ele é constituinte da proteína, auxilia no processo fotossintético, tem participação na molécula de clorofila, além disso, apresenta efeitos na produção e concentração de compostos nitrogenados, valor nutritivo e qualidade da forragem, por isso a adubação nitrogenada é uma opção aos pecuaristas quando se deseja aumentar a produtividade (MACEDO et al., 2012a).

Para ter forragem de boa qualidade, é necessário maneja-la com adubos, em doses adequadas, e formas ideais, para que os nutrientes absorvidos possam integrar o metabolismo da planta e ela possa expressar seu máximo potencial. Desta forma, objetivou-se avaliar três doses de adubação nitrogenada sobre as 
características morfogênicas e produtivas do sorgo híbrido SS-318.

\section{MATERIAL E MÉTODOS}

O experimento foi desenvolvido em área pertencente à Fazenda Experimental da Universidade Federal do Oeste do Pará - UFOPA, localizada na rodovia Santarém - Curuá una, Km 37, em Santarém, Pará, situada na latitude de $2^{\circ} 41^{\prime} 6.44^{\prime \prime} \mathrm{S}$ e longitude de $54^{\circ} 32^{\prime} 22.03^{\prime \prime} \mathrm{W}$.

A classificação climática da região norte caracteriza-se com tipo Am de acordo com a classificação de Kõppen, com clima quente e úmido, e temperaturas médias, máximas e mínimas anuais oscilando, respectivamente, entre 25 e $26{ }^{\circ} \mathrm{C}, 30$ e $31^{\circ} \mathrm{C}$ e 21 e $23{ }^{\circ} \mathrm{C}$, enquanto que a precipitação pluviométrica apresenta valores anuais oscilantes em torno de 2.000 mm, com distribuição irregular durante os meses, mostrando a ocorrência de dois períodos nítidos de chuvas, com o mais chuvoso abrangendo o período de dezembro a junho, concentrando mais de $70 \%$ da precipitação anual, e outro com menos chuva, compreendendo os demais meses do ano (OLIVEIRA JÚNIOR; CORREA, 2001).

Para o desenvolvimento do trabalho foi utilizado o sorgo híbrido SS-318 (Sorghum bicolor). $\bigcirc$ experimento foi conduzido no período de junho a setembro de 2015, com semeadura realizada manualmente.

A área experimental foi preparada inicialmente com duas gradagens. As características químicas do solo da área experimental no momento da semeadura estão apresentadas na Tabela 1.

Tabela 1. Características químicas do solo da área de cultivo do sorgo.

\begin{tabular}{|c|c|c|c|c|c|c|c|c|c|c|c|}
\hline \multirow{2}{*}{$\begin{array}{l}\text { Prof. } \\
\mathrm{cm}\end{array}$} & $\mathrm{pH}$ & M.O. & K & $P$ & $\mathrm{Ca}$ & $\mathrm{Mg}$ & $\mathrm{Al}$ & $\mathrm{H}+\mathrm{Al}$ & SB & $T$ & \multirow{2}{*}{$\begin{array}{l}\mathrm{V} \\
\%\end{array}$} \\
\hline & $\mathrm{CaCl}_{2}$ & dag/kg & \multicolumn{2}{|c|}{$\mathrm{mg} / \mathrm{dm}^{3}$} & ---- & --- & $---c m$ & $/ \mathrm{dm}^{3}-$ & ---- & - & \\
\hline $0-20$ & 5,8 & 1,99 & 68 & 36,08 & 2,10 & 1 & 0,10 & 3,24 & 3,27 & 6,51 & 50,30 \\
\hline $20-40$ & 5,7 & 1,29 & 46 & 28,18 & 1,80 & 1 & 0,10 & 2,32 & 2,92 & 5,24 & 55,69 \\
\hline
\end{tabular}

O delineamento experimental foi inteiramente casualizado, sendo três tratamentos: 80, 120 e $160 \mathrm{~kg} \cdot \mathrm{ha}^{-1}$ de nitrogênio e quatro repetições. Utilizou-se a dose de adubação nitrogenada recomendada para o estado do Pará de 
$80 \mathrm{~kg} \cdot \mathrm{ha}^{-1}$ e duas doses superiores (120 e 160 kg.ha-1), segundo Cravo et al. (2007), com produtividade esperada de 40 a 60 t.ha-1 de matéria verde.

As parcelas experimentais foram de $7 \mathrm{x}$ 3,2 m (22,4 $\left.\mathrm{m}^{2}\right)$, sendo o espaçamento entre as fileiras de $75 \mathrm{~cm}$ e entre plantas de $50 \mathrm{~cm}$, com profundidade de semeadura de 3 a $5 \mathrm{~cm}$, utilizando 5 sementes por cova, para fins de avaliação foram descartadas as duas linhas laterais, além de um metro das extremidades de cada parcela, totalizando uma área útil de $7,5 \mathrm{~m}^{2}$. Aos 10 dias foi realizado desbastes nas parcelas, deixando uma planta por cova, conforme Magalhães et al. (2010).

Para a adubação nitrogenada utilizouse ureia como fonte, para a adubação fosfatada e potássica foi utilizado superfosfato simples e cloreto de potássio como fonte respectivamente, a fim de atender $80 \mathrm{~kg} \cdot \mathrm{ha}^{-1}$ de $\mathrm{P}_{2} \mathrm{O}_{5}$ e $60 \mathrm{~kg} \cdot \mathrm{ha} \mathrm{a}^{-1}$ de $\mathrm{K}_{2} \mathrm{O}$. Os adubos foram aplicados 50\% na semeadura e 50\% após 35 dias do plantio.

Aos 35 dias foi aferida a altura das plantas, o número de perfilho e número de folhas. Aos 90 dias foram avaliados a altura das plantas, número de perfilhos, número de folhas, número de folhas mortas, acamamento (obtido pela contagem das plantas que apresentaram um ângulo de inclinação maior que $45^{\circ}$ em relação ao eixo vertical), número de plantas quebradas (obtido pela contagem das plantas quebradas por ocasião do corte) e número de plantas por parcela (número de plantas na área da parcela contadas por ocasião do corte).

Para determinação da produção de matéria verde, foram coletadas 10 plantas de sorgo de cada parcela, cortadas a aproximadamente $20 \mathrm{~cm}$ acima do nível do solo, depois essa amostra foi pesada e a partir disso foi obtida a produção de massa verde. Para a determinação da matéria seca, as amostras foram separadas em folhas, colmo e panícula, pesadas e levadas em estufa de circulação forçada de ar a $65^{\circ} \mathrm{C}$ por 72 h, em seguida pesados novamente, conforme Alcântara et al. (2011).

Os resultados foram submetidos à análise estatística utilizando-se o Sistema de Análises de Variância (SISVAR) e, para a comparação de médias foi utilizado o teste de Tukey, ao nível de 5\% de significância e análise de regressão das variáveis: número de folhas vivas, número 
de perfilhos e altura, quando apresentaram coeficientes significativos.

\section{RESULTADOS E DISCUSSÃO}

Das variáveis analisadas aos 35 dias, o número de folhas vivas e número de perfilhos não sofreram efeito em função dos níveis de nitrogênio, no entanto a altura foi significativa $(p<0,05)$ (Figura 1). Número de folhas vivas e número de perfilhos por planta apresentaram efeito linear decrescente com o aumento das doses de nitrogênio, correspondendo a redução de 0,61 folhas vivas por planta e 0,21 perfilhos por planta, com o aumento em cada kg de $\mathrm{N}$ aplicado. A variável altura apresentou redução quadrática (Figura 2). Aos 90 dias o número de folhas vivas, número de perfilhos e altura diferiram estatisticamente $(p<0,05)$ entre as doses de adubação nitrogenada, enquanto o número de folhas mortas, população de plantas, plantas acamadas e quebradas não demonstraram resultados significativos (Tabela 2). Com relação à biomassa, a matéria verde da folha, colmo e panícula, matéria verde total e a matéria seca da folha, colmo e panícula não sofreram efeito significativo entre as doses de nitrogênio aplicadas (Tabela 3).

O número de folhas vivas (NFV) não sofreu efeito entre os tratamentos aos 35 dias, com valores de 12,91, 12,4 e 11 folhas. planta ${ }^{-1}$ para 80, 120 e $160 \mathrm{~kg} \mathrm{ha}^{-1} \mathrm{a}$ de nitrogênio respectivamente (Figura 1). Assim, o aumento das doses de nitrogênio não favoreceu o aumento na produtividade de folhas. Esses resultados são semelhantes aos apresentados por Silva et al. (2012), que ao avaliarem doses de nitrogênio (50 e 100 kg.ha-1) em cobertura nos híbridos de sorgo forrageiro BRS801 e 0734006, cultivados em vasos ao ar livre, não encontraram diferença significativa para o número de folhas vivas entre os tratamentos.

○úmero de perfilhos (NP) aferidos aos 35 dias não apresentaram diferença estatística $(p>0,05)$ entre os tratamentos, cujas médias foram 1,34, 1,49 e 1,26 perfilhos. planta-1 para os tratamentos com 80, 120 e 160 kg.ha-1 de nitrogênio respectivamente, demonstrando que o incremento nas doses de nitrogênio não foi determinante para a produtividade desta variável no estádio vegetativo inicial. 
Figura 1. Número de folhas vivas (NFV) (A), de perfilho (NP) (B) e altura de sorgo (C) em função dos níveis de adubação nitrogenada aos 35 dias (Colunas com letras iguais, minúsculas, não diferem estatisticamente, pelo teste de Tukey $(p>0,05)$.

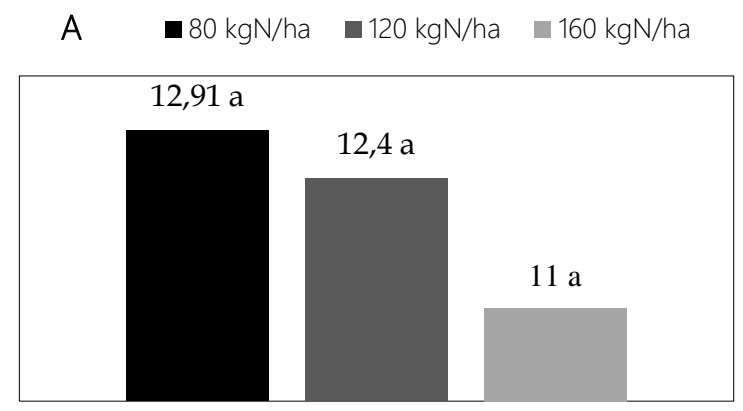

NFV $\left(n^{\circ}\right.$.planta-1)

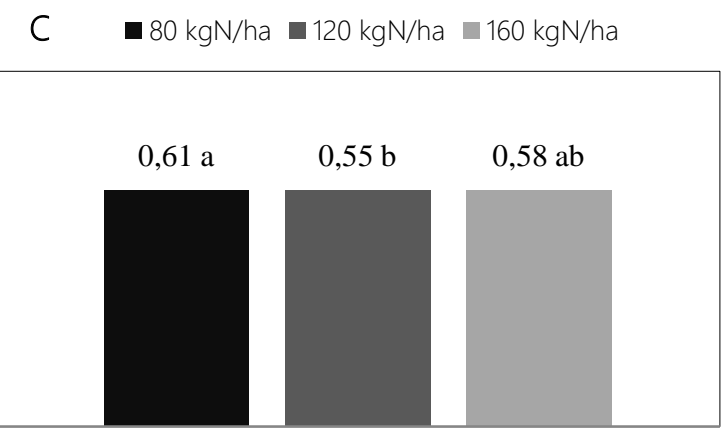

Altura (m)

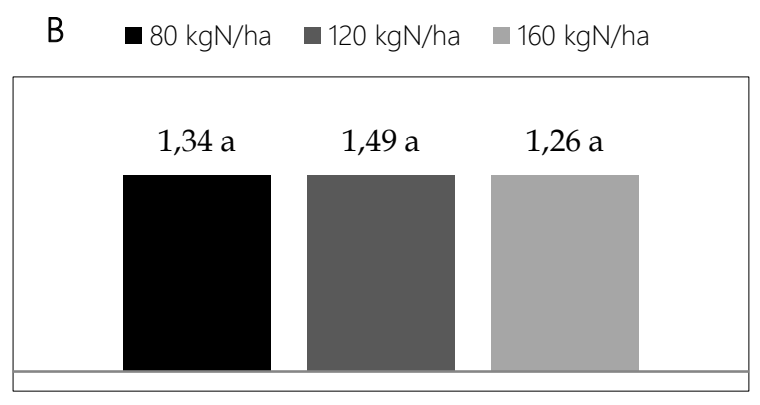

$N P\left(n^{\circ}\right.$. planta-1)

A altura diferiu $(p<0,05), \quad$ adubações nitrogenadas $(0,50,100,150$ e apresentando valor de 0,61 m no $\left.200 \mathrm{~kg} \mathrm{ha}^{-1}\right)$, cultivado em vasos ao ar livre tratamento com $80 \mathrm{~kg} \cdot \mathrm{ha}^{-1}$ de nitrogênio, e com capacidade de 6 kg, não o qual foi superior aos demais tratamentos, que apresentaram médias de 0,55 m e 0,58 m para 120 e 160 kg.ha` ${ }^{1}$ de adubação nitrogenada respectivamente. Parente et al. (2014) estudando a produtividade do sorgo forrageiro submetido a diferentes observaram variação na altura em função do aumento nos níveis de nitrogênio.

Observou-se relação inversa entre a adubação nitrogenada e o número de folhas, à medida que se aumentou as doses de nitrogênio o número de folhas diminuiu, da mesma forma, o número de 
perfilho e altura obtiveram seu ponto de máxima no tratamento com $80 \mathrm{~kg} \cdot \mathrm{ha}^{-1}$ de nitrogênio, no entanto, o número de folhas mortas obteve sua maior produtividade com $120 \mathrm{~kg} \cdot \mathrm{ha}^{-1}$ de adubação nitrogenada.

Figura 2. Número de folhas vivas (A), de perfilhos (B) e altura do sorgo (C) aos 90 dias após a emergência em função da aplicação de doses de nitrogênio.

A
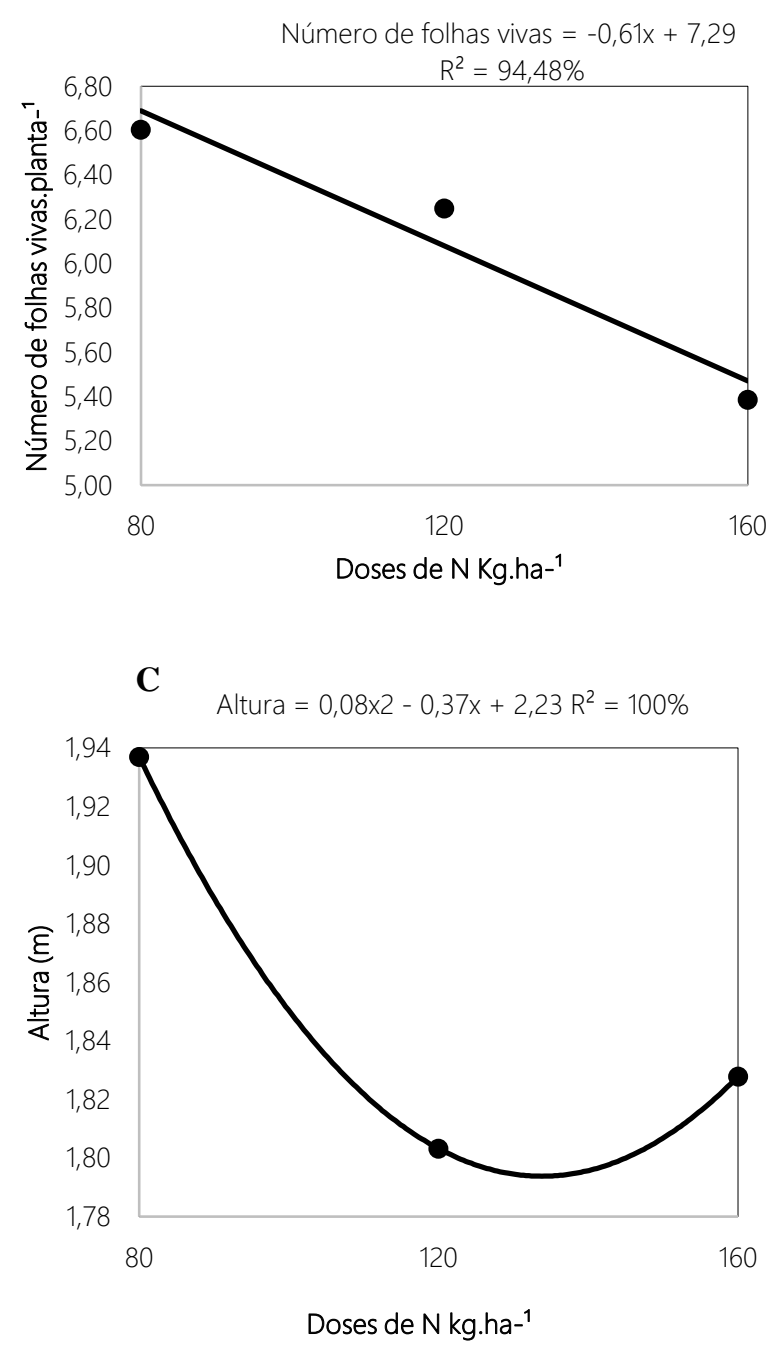

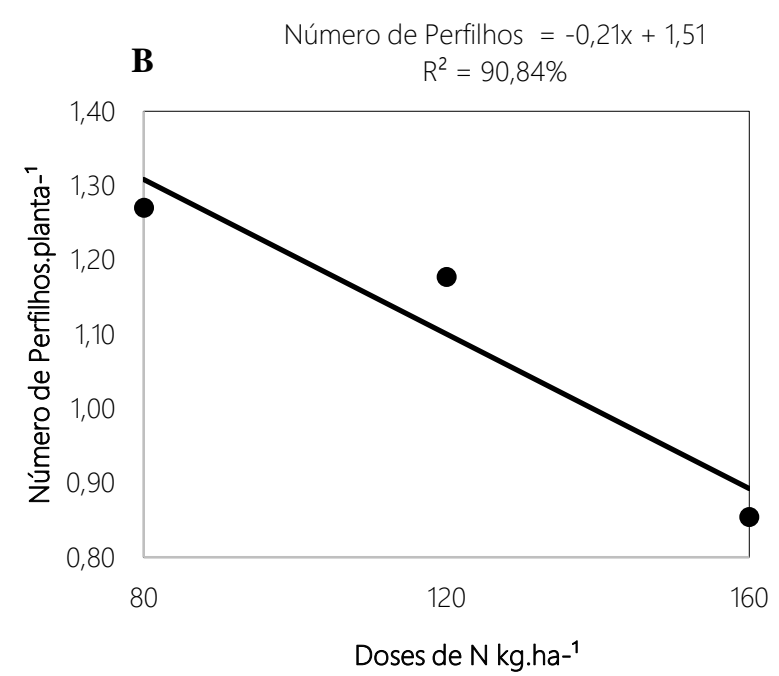


Tabela 2. Variáveis morfométrica do Sorgo aos 90 dias.

\begin{tabular}{|c|c|c|c|c|}
\hline \multirow{2}{*}{ Variáveis } & \multicolumn{3}{|c|}{ Tratamentos } & \multirow{2}{*}{ Probabilidade } \\
\hline & 80 kgN.ha-1 & 120 kgN.ha-1 & 160 kgN.ha-1 & \\
\hline NFV (n. planta $\left.^{-1}\right)$ & $6,60 a$ & $6,25 a b$ & $5,39 b$ & 0,016 \\
\hline NFM (n $n^{0}$.planta-1) & $8,95 a$ & $8,99 a$ & $8,72^{a}$ & 0,855 \\
\hline NP (n $n^{\circ} \cdot$ planta $\left.^{-1}\right)$ & $1,27 a$ & $1,18 a$ & $0,85 b$ & 0,003 \\
\hline $\operatorname{ALT}(\mathrm{m})$ & $1,94 a$ & $1,80 b$ & $1,83 b$ & 0,008 \\
\hline PP $\left(n^{0}\right.$. parcela $\left.{ }^{-1}\right)$ & $60,75 a$ & $62,75 a$ & $59,25 a$ & 0,763 \\
\hline ACAM (n. parcela $\left.{ }^{-1}\right)$ & $1,31 a$ & $1,18 a$ & $1,00 a$ & 0,589 \\
\hline QUEB (n. parcela-1) & $1,25 a$ & $1,72 a$ & $1,67 a$ & 0,669 \\
\hline
\end{tabular}

Onde: NFV - número de folhas vivas, NFM - número de folhas mortas, NP - número de perfilhos, ALT - altura, PP - população de plantas, ACAM - plantas acamadas, QUEB - plantas quebradas. Médias seguidas das mesmas letras, nas linhas, não diferem entre si pelo teste Tukey $(p>0,05)$.

Tabela 3. Biomassa do sorgo híbrido SS318 em função de doses de adubação nitrogenada.

\begin{tabular}{|c|c|c|c|c|}
\hline \multirow[t]{2}{*}{ Variáveis } & \multicolumn{3}{|c|}{ Tratamentos } & \multirow[t]{2}{*}{ Probabilidade } \\
\hline & $80 \mathrm{kgN} \mathrm{ha}^{-1}$ & $120 \mathrm{kgN} \cdot \mathrm{ha}^{-1}$ & 160 kgN.ha-1 & \\
\hline MVF (g.planta-1) & $46,11 a$ & $51,25 a$ & $48,63 a$ & 0,497 \\
\hline MVC (g.planta ${ }^{-1}$ ) & $199,28 a$ & $179,63 a$ & $206,21 a$ & 0,186 \\
\hline MVP (g.planta-1) & $166,35 a$ & $179,00 a$ & $171,43 a$ & 0,597 \\
\hline MVT (g.planta-1) & $411,73 a$ & $409,88 a$ & $426,27 a$ & 0,837 \\
\hline MSF (g.planta ${ }^{-1}$ ) & $16,40 a$ & $18,06 a$ & $15,37 a$ & 0,369 \\
\hline MSF (\%) & $35,73 a$ & $35,24 a$ & $31,95 a$ & 0,412 \\
\hline MSC (g.planta-1) & $96,61 a$ & $76,53 a$ & $99,75 a$ & 0,070 \\
\hline MSC (\%) & $47,69 a$ & $41,53 a$ & $46,93 a$ & 0,124 \\
\hline MSP (g.planta-1) & $123,16 a$ & $128,99 a$ & $123,73 a$ & 0,781 \\
\hline MSP (\%) & $74,32 a$ & $71,85 a$ & $72,89 a$ & 0,414 \\
\hline
\end{tabular}

Onde: MVF - matéria verde da folha, MVC - matéria verde do colmo, MVP - matéria verde da panícula, MSF - matéria seca da folha, MSC matéria seca do colmo, MSP - matéria seca da panícula. Médias seguidas das mesmas letras, nas linhas, não diferem entre si pelo teste Tukey $(p$ $>0,05)$.

Os valores para as variáveis: número de folhas vivas, número de perfilho e altura aferidos aos 90 dias diferiram significativamente entre os tratamentos e evidenciaram que o tratamento com 80 $k g \cdot h a^{-1}$ de nitrogênio foi o mais eficiente, apresentando valores superiores para todas as variáveis avaliadas (Tabela 2). Os valores obtidos nesse experimento corroboram os de Macedo et al. (2012b) 
que observaram que a medida que se elevam os níveis de adubação nitrogenada ocorre uma diminuição na produção de folhas de sorgo forrageiro.

As características que determinam o crescimento de perfilhos são determinadas por efeito genético, e a taxa de aparecimento foliar está diretamente relacionada com a emissão de novos perfilhos (Silva et al., 2012), isso explica a maior produtividade de folhas do sorgo ter aumentado de acordo com o perfilhamento nas plantas.

Com relação à altura, Perazzo et al. (2013) destacaram que o sorgo com porte alto tende a ter mais biomassa e consequentemente maior porcentagem de colmo e lâmina foliar, por outro lado, quando possui porte baixo têm melhor produção de panícula e matéria seca. Outro estudo desenvolvido por Goes et al. (2011) em que avaliaram doses de nitrogênio na proporção 0, 20, 40, 60 e 80 kg.ha-1 encontraram médias de 140,36 à $142,88 \mathrm{~cm}$ para a altura do sorgo granífero, sugerindo que as doses de nitrogênio avaliadas neste trabalho promoveram maior altura do sorgo, onde encontrou-se valores de 194, 180 e 183 cm para 80, 120 e $160 \mathrm{~kg} \cdot \mathrm{ha}^{-1}$ de nitrogênio respectivamente.

O número de folhas mortas não teve efeito entre os tratamentos, apresentando valores de 8,95, 8,99 e 8,72 folhas.planta-1 para 80, 120 e 160 kg.ha-1 de nitrogênio respectivamente, esses resultados se opõem aos encontrados por Silva et al. (2012) que ao avaliar adubação nitrogenada em sorgo forrageiro nas doses de 50 e 100 kg.ha ${ }^{-1}$ encontraram diminuição no número de folhas mortas a medida que se elevou os níveis de nitrogênio.

A população de plantas não variou em função dos níveis de nitrogênio, cujas médias foram 60,75, 62,75 e 59,25 plantas.parcela-1 para 80, 120 e 160 kg.ha' 1 respectivamente. $\bigcirc$ acamamento e plantas quebradas não diferiram entre os tratamentos, demonstrando que as doses de nitrogênio não influenciaram nessas variáveis. Segundo Caires e Milla (2016) quanto maior a altura das gramíneas maior é a probabilidade de plantas acamadas, no entanto, no presente estudo a altura não influenciou no acamamento. 
Quanto à biomassa do sorgo, observou-se que o aumento nos níveis de nitrogênio avaliados não influenciou a produtividade $(p>0,05)$ para nenhuma das variáveis (matéria verde da folha, matéria verde do colmo, matéria verde da panícula, matéria verde total, matéria seca da folha, matéria seca do colmo, matéria seca da panícula), no entanto a média de produção para matéria verde total foi 411,73, 409,88 e 426,27 g.planta ${ }^{-1}$ (80, 120 e $160 \mathrm{~kg} \cdot \mathrm{ha}^{-1}$ de nitrogênio respectivamente) (Tabela 3).

Os resultados dessa pesquisa discordaram dos obtidos por Jardim et al. (2015) que ao avaliarem a biomassa verde com incrementos na adubação nitrogenada $(0,50,100,150$ e 200 kg.ha-1) na cultura do sorgo sacarino, encontraram resultados significativos para massa fresca da folha (resultados variaram de 6708 a 9472 kg.ha-1), massa fresca do colmo (resultados variaram de 52, 846 a $69.356 \mathrm{~kg} \mathrm{ha}^{-1}$ ) e massa fresca da panícula (resultados variaram de 546 à 943 kg.ha$\left.{ }^{1}\right)$, obtendo maiores produtividades a medida que se aumentava os teores de nitrogênio. Em outro trabalho, Tavian et al. (2014) observaram incremento na produtividade da massa fresca da folha, massa fresca do colmo e massa fresca da panícula de sorgo forrageiro a medida que se elevou os teores de nitrogênio (0, 50, 100, 150 e 200 kg.ha-1).

Também não houve incremento na produção de matéria seca das partes integrantes do sorgo com o aumento das doses de nitrogênio, cujas médias foram de 16,40, 18,06 e 15,37 g. planta $^{-1}$ para matéria seca da folha, 96,61, 76,53 e 99,75 g.planta-1 para matéria seca do colmo, 123,16, 128,99 e 123,73 g. planta $^{-1}$ para matéria seca da panícula com 80, 120 e 160 kg.ha-1 de nitrogênio respectivamente. Esses resultados diferem dos obtidos por Benedetti et al. (2015) que avaliando doses de nitrogênio (0, 50, 100, 150 e 200 kg.ha $\left.{ }^{1}\right)$ no sorgo sacarino encontraram resultados significativos para matéria seca da folha, com variação de 361 a 477 kg.ha` 1, matéria seca do colmo, com médias variando de 20081 a 26355 kg.ha-1 e matéria seca da panícula de 49 a 84 kg.ha 1.

\section{CONCLUSÃO}

$\bigcirc$ aumento nas doses de nitrogênio não acompanhou o incremento nos 
caracteres produtivos de sorgo híbrido

SS-318, sendo que doses acima de 80 $\mathrm{kg} \cdot \mathrm{ha}^{-1}$ se traduzem em perdas para $\mathrm{O}$ agricultor.

\section{REFERÊNCIAS}

ALCÂNTARA, H.P.; CARVALHO, E.R.; REZENDE, P.M.; SANTOS, J.P.; ANDRADE, M.J.B. Rendimento e composição química da forragem de sorgo em diferentes épocas de semeadura. Ciência e Agrotecnologia, v.35, p.728-734, 2011.

BASSO, F.C.; ANDREOTTI, M.; CARVALHO, M.P.; LODO, B.N. Relações entre produtividade de sorgo forrageiro e atributos físicos e teor de matéria orgânica de um latossolo do cerrado. Pesquisa Agropecuária Tropical, v.41, p.135-144, 2011.

BENEDETTI, P.; DOMINGUES, E.L.C.; SANTOS JUNIOR, D.D.; JARDIM, C.A.; FRANCO, C.F. Influência do nitrogênio na cultura do sorgo BRS 506 para a produção de biomassa. Ciência \& Tecnologia: Fatec-JB, v.7, p.131-135, 2015. Suplemento.

BUSO, W.H.D.; MORGADO, H.S.; SILVA, L.B.; FRANÇA, A.F.S. Utilização do sorgo forrageiro na alimentação animal. PUBVET, v.5, ed.170, art.1145, 2011.

CAIRES, E. F.; MILLA, R. Adubação nitrogenada em cobertura para o cultivo de milho com alto potencial produtivo em sistema de plantio direto de longa duração. Revista solos e Nutrição de plantas, v. 75, p.87-95, 2016.
CRAVO, M.S.; VIÉGAS, I.J.M.; BRASIL, E.C. (Ed.). Recomendações de adubação e calagem para o Estado do Pará. Belém, PA: Embrapa Amazônia Oriental, 2007, 262p.

GOES, R.J.; RODRIGUES, R.A.F.; ARF, O.; ARRUDA, O.G.; VILELA, R.G. Fontes e doses de nitrogênio em cobertura, no sorgo granífero na safrinha. Revista Brasileira de Milho e Sorgo, v.10, p. 121129, 2011.

GOMES, S.O.; PITOMBEIRA, J.B.; NEIVA, J.N M.; CÂNDIDO, M.J.D. Comportamento agronômico e composição químicobromatológico de cultivares de sorgo forrageiro no Estado do Ceará. Revista Ciência Agronômica, v.37, p.221-227, 2006.

JARDIM, C.A.; PEREIRA, S.A.P.; PEREIRA, J.G.B.; FRANCO, C.F.; MINGOTTE, F.L.C. Adubação nitrogenada na produção de sorgo sacarino BRS 506 para alimentação animal. Ciência \& Tecnologia: Fatec-JB, v. 7, p.37-41, 2015. Suplemento

MACEDO, C.H.O.; ANDRADE, A.P.; SANTOS, E.M.; SILVA, D.S.; SILVA, T.C.; EDVAN, R.L. Perfil fermentativo e composição bromatológica de silagens de sorgo em função da adubação nitrogenada. Revista Brasileira Saúde e Produção Animal, v.13, p.371-382, 2012b.

MACEDO, C.H.O.; SANTOS, E.M.; SILVA, T.C.; ANDRADE, A.P.; SILVA, D.S.; SILVA, A.P.G.; OLIVEIRA, J.S. Produção e composição bromatológica do sorgo (Sorghum bicolor) cultivado sob doses de nitrogênio. Archivos de Zootecnia, v. 61, p.209-216. 2012a. 
MAGALHÃES, R.T.; GONÇALVES, L.C.; BORGES, I.; RODRIGUES, J.A.S.; FONSECA, J.F. Produção e composição bromatológica de vinte e cinco genótipos de sorgo (Sorghum bicolor (L.) Moench). Arquivo Brasileiro de Medicina Veterinária e Zootecnia, v.62, p.747-751, 2010.

OLIVEIRA JÚNIOR, R.C.; CORREA, J.R.V. Aptidão agrícola dos solos de Município de Belterra, Estado do Pará. Belém, PA: Embrapa Amazônia Oriental, 2001, 21p. (Circular técnica, n.91).

PARENTE, H.N.; SILVA JUNIOR, O.R.; BANDEIRA, J.R.; PARENTE, M.O.M.; RODRIGUES, R.C.; ROCHA, K.S.; GOMES, R.M.S. Produtividade do sorgo forrageiro em função de quantidades crescentes de adubação fosfatada e nitrogenada. Revista Trópica: Ciências Agrárias e Biológicas, p.1-10, v.08, 2014.

PERAZZO, A.F.; SANTOS, E.M.; PINHO, R.M.A.; CAMPOS, F.S.; RAMOS, J.P.F.; AQUINO, M.M.; SILVA, T.C.; BEZERRA, H.F.C. Características agronômicas e eficiência do uso da chuva em cultivares de sorgo no semiárido. Ciência Rural, v.43, p.1771-1776, 2013

REZENDE, P.M.; ALCANTARA, H.P.; PASSOS, A.M.A.; CARVALHO, E.R.; BALIZA, D.P.; OLIVEIRA, G.T.M. Rendimento forrageiro da rebrota do sorgo em sistema de produção consorciado com soja. Revista Brasileira de Ciências Agrárias, v.6, p.362-368, 2011.

SILVA, W.L.; BASSO, F.C.; RUGGIERI, A.C.; VIEIRA, B.R.; ALVES, P.L.C.A.; RODRIGUES, J.A.S. Características morfogênicas e estruturais de híbridos de sorgo submetidos a adubação nitrogenada.
Revista Brasileira de Ciências Agrárias, v.7, p.691-696, 2012.

TAVIAN, A.F.; FREITAS, D.S.; GONÇALVES, B.C.C.; MARTINS, F.A.G.; JARDIM, C.A.; FRANCO, C.F. Adubação nitrogenada no desenvolvimento de sorgo forrageiro. Ciência \& Tecnologia: Fatec-JB, v. 6, p. 3337, 2014. Suplemento. 